Article

\title{
Horizontal Coordination of I-LNGOs in the Humanitarian Supply Chain: An Evolutionary Game Approach
}

\author{
Fan Chen ${ }^{1}$, Sen Liu ${ }^{2, *}$ and Andrea Appolloni ${ }^{3,4, *(\mathbb{D})}$ \\ 1 School of Management, Huazhong University of Science and Technology, Wuhan 430074, China; \\ d201780928@hust.edu.cn \\ 2 School of Logistics, Yunnan University of Finance and Economics, Kunming 650221, China \\ 3 Department of Management and Law, Faculty of Economics, University of Rome Tor Vergata, \\ 00133 Rome, Italy \\ 4 Institute for Research on Innovation and Services for Development (IRISS), \\ National Research Council (CNR), 80134 Naples, Italy \\ * Correspondence: liusencool@ynufe.edu.cn (S.L.); andrea.appolloni@uniroma2.it (A.A.)
}

Received: 21 May 2020; Accepted: 7 July 2020; Published: 23 July 2020

\begin{abstract}
Disasters accompanied by heavy casualties and huge economic losses directly result in the disruption or delay of economic development. Considering the urgent need for reducing losses and accelerating the process of social recovery, international nongovernment organizations (INGOs) and local NGOs (LNGOs) with different resource endowments should achieve organizational coordination to improve the relief efficiency and sustainability of the humanitarian supply chain. Due to conflicting interests and expectations, this coordination is hard to achieve. In this study, we first establish an evolutionary game model between INGOs and LNGOs to determine the influencing factors and explore the interaction of NGOs in a dynamic way. Our results show that: (1) coordination by resource sharing can improve the sustainability of the humanitarian supply chain; (2) coordination willingness is affected by the behavior of other players, which can nevertheless achieve equilibrium under certain conditions; and (3) the important factors and optimal strategies of players are highlighted in the dynamic model. This study provides several insights into the theory of organizational coordination in the humanitarian supply chain regarding sustainability.
\end{abstract}

Keywords: sustainability; humanitarian supply chain; NGO; coordination; evolutionary game

\section{Introduction}

Tropical storm "Harvey" affected six million people in south Texas and disrupted traffic on the ground and in the air in 2017. In 2018, typhoon "Shanzhu" affected nearly 3 million people in China, resulting in a direct economic loss of 5.2 billion dollars. With the intensification of human activities, the frequency and impact of disasters have grown exponentially in the last few decades [1]. A large number of heavy casualties and huge economic losses due to disasters directly result in the disruption or delay of economic development [2]. Sustainable social development cannot be separated from a stable environment. To cut losses and accelerate the process of social recovery, there is a greater focus on the sustainability of the humanitarian supply chain, which consists of donors, host governments, international and local nongovernment organizations (INGOs and LNGOs), and the military and private sectors engaged in disaster relief activities [3-5]. Considering the aim of helping populations regain their life status and contribute to social, economic, and ecological development, the UN (2015) proposed that the concept of sustainable development be incorporated into the work of disaster relief [6]. The combination of sustainability and the traditional disaster supply 
chain will help strengthen the long-term capacity of humanitarian organizations and promote their responsiveness [7]. However, extreme challenges exist in all stages of the disaster relief cycle. Although investment and planning by humanitarian actors in the mitigation and preparedness phases can reduce the direct impact of disasters on human life and property, the efficiency of post-disaster relief can be difficult to determine due to poor coordination [2]. The sustainability of the humanitarian supply chain relies on responsible communication and coordination [8]. Therefore, information transparency, enhanced communication, and the trust derived from coordination contribute to more sustainable development [9]. Thus, it can be inferred that organizational coordination is an effective method to improve the sustainability of the humanitarian supply chain.

INGOs and LNGOs in the humanitarian supply chain act as bridges connecting all components with their beneficiaries and undertake similar tasks, such as gathering social resources, disseminating the right information, and developing recovery projects [10]. Since each NGO has its own culture, interest, and operation method, most of them usually manage their rescue activities independently [11]. In addition, in a temporary relief chain without mutual trust, individual NGOs engage in a competitive relationship because of limited donations [12]. However, under a complex relief environment and incomplete information, independent relief actions that do not consider other organizations in large-scale disasters can result in a duplication of efforts and waste of resources [13,14]. For example, the poor coordination among the involved humanitarian actors led to severe overstock and, simultaneously, to a shortage of relief materials in the 2008 Wenchuan earthquake, which seriously affected the efficiency of aid and recovery areas. Considering the sustainability of relief operations, horizontal coordination among NGOs has been highlighted by many humanitarian practitioners $[7,10,11]$.

Current researchers acknowledge that horizontal coordination in the humanitarian supply chain is conducive to economies of scale, reducing individual operational costs [13]. However, the application in NGOs is very limited. Scholars propose that INGOs and LNGOs have a complementary relationship with regard to resources on the basis of their organizational nature [15]. The coordination between INGOs and LNGOs achieved by sharing tangible and intangible resources can enhance the utilization of these resources $[16,17]$. Moreover, working with local networks can be regarded as an effective method to strengthen sustainability because the benefits of coordination contribute to the organization capacity [18]. As a matter of fact, large factors hinder coordination, such as the absence of trust, communication barriers, and coordination costs $[13,15,19]$. Most existing studies try to reveal drivers and challenges of coordination among NGOs through case studies or investigation analyses $[10,15,20]$. Under the interaction of resource sharing, the dynamic nature of coordination tends to get overlooked. In this context, our study addresses three questions:

(1) What is the motivation for the coordination between INGOs and LNGOs in the humanitarian supply chain?

(2) How should optimal behavior in the dynamic mechanism be adopted?

(3) What are the interventions that affect coordination?

This paper attempts to address this gap by developing an evolutionary game model to quantitatively analyze horizontal coordination strategies between INGOs and LNGOs. Evolutionary game theory (EGT) is a modification of traditional game theory by Darwin's theory of biological evolution [21]. The core concepts of EGT are the evolutionary stable strategy (ESS) and the replication dynamic. That is, players with bounded rationality adjust their strategies based on gains from previous behaviors. If one strategy yields more gains, players tend to adopt this strategy and eventually move toward a stable state through repeated games [22]. EGT is widely used in the fields of economics and sociology to study conflicts and cooperation between decision-makers [23,24]. Many scholars use EGT to manage supply chain coordination and develop long-term strategic stability. For example, Zhi et al. [25] proposed an evolutionary game model to investigate the coordination of suppliers and manufacturers to reduce carbon emissions. Chen et al. [26] used an evolutionary game framework 
to explain why there is significant variability in the effectiveness of monitoring interventions to induce process compliance by healthcare workers in hospitals. In the literature on the humanitarian supply chain, evolutionary games between humanitarian organizations have also been explored. $\mathrm{Du}$ and Qian [27] illustrated the relationship between governments and nonprofit organizations and developed an evolutionary game model to promote coordination in disaster mobilization. Li et al. [6] applied EGT to address the coordination between the private sector and humanitarian organizations and highlighted the significant positive impact of trust. Considering the urgency of disaster relief and the limitation of resources, conflicts of interest also exist between INGOs and LNGOs during the coordination process. The evolutionary game method provides a systematic and dynamic perspective to analyze the choice of strategy over time.

In this study, we first determine the game relationship between INGOs and LNGOs to establish a model. Then, we discuss the ESS and analyze the evolutionary path stimulated by different factors. The research results show that the behavior of players can interact with each other. A long-term coordinated relationship can be achieved under certain conditions. The findings also highlight that enhancing sharable resources and the benefits of coordination are extremely effective methods to stimulate players to maintain coordination. Through a numerical experiment, we conclude that the initial state of players only has a short-term impact on the selection of strategy, whereas stable conditions can influence their decision making for the long-term. This study has both theoretical and practical contributions. We extend the coordinated actors to INGOs and LNGOs and develop an evolutionary game model to systematically analyze the coordination mechanism. Key factors affecting the behavior of players are determined. By adding the dynamic perspective, the consideration of critical factors affecting coordination is closer to reality. The conclusions provide theoretical guidance for managing the coordination strategy between INGOs and LNGOs by capturing the dynamic interactive behaviors and predicting the evolutionary trend.

The remainder of the article is organized as follows. Section 2 reviews the relevant critical literature. Section 3 describes the framework of the evolutionary game model. In Section 4, we analyze the evolution tendency of players and the equilibrium conditions of the model. Section 5 discusses the results of a numerical simulation experiment and proposes some implications. The conclusions and suggestions for future research are presented in Section 6.

\section{Literature Review}

\subsection{Coordination in Humanitarian Supply Chains}

When referring to the commercial supply chain, sustainability entails various stakeholders to address the development objectives associated with economic, environmental, and social dimensions [22]. For example, De A et al. [28,29] proposed that sustainability aspects should be incorporated into shipping route design by reducing the emission of greenhouse gases from vessels. Some shipping companies that act against sustainable approaches may have a higher cost [30]. Goswami M et al. [31] integrated environment performance into measures of the sustainable performance of third-party logistics providers and indicated that when information exchange occurs between logistics operators and the manufacturer, effective transport planning and distribution network design in conjunction with commodity considerations can improve the sustainability of the supply chain. From the perspective of supply chain management, performance is affected by the behavioral tendencies of different stakeholders, such as manufacturers, distributors, and consumers [32]. Decision makers should balance different interests from various stakeholders to achieve sustainable performance [33]. According to Bealt et al. [34], organizational coordination can be effectively applied as a method to address the management of stakeholders. Tong and Li [35] also demonstrated that the internal coordination of the supply chain could promote sustainable development by encouraging a green manufacturer to develop a product with a higher degree of greenness and increasing sales of that product. 
Similar to the commercial supply chain, coordination among multiple agents is also highlighted by researchers $[12,14,36]$ as measures for improving the sustainability of the humanitarian supply chain. According to Haavisto and Kovács [7], poor coordination among humanitarian actors not only causes high operation costs for humanitarian organizations and waste of limited resources but also decreases the efficiency of relief activities and prolongs the suffering of humans, which acts against their social responsibility and hinders long-term development. Based on the type of actors in the humanitarian supply chain, organizational coordination can be divided into vertical coordination and horizontal coordination [13]. Vertical coordination refers to coordinating with upstream or downstream organizations. The effect of reducing the cost of the humanitarian supply chain and maximizing relief benefits has undergone extensive study $[37,38]$. For example, Nikkhoo et al. verified that coordination between upstream manufacturers and downstream NGOs in procurement can improve the satisfaction level of the affected areas [39]. Joint decision-making of inventory by suppliers and relief organizations significantly minimizes the total cost and strengthens risk management in disasters [3]. A distribution model merging multiple humanitarian stakeholders' preferences can improve the reliability of the humanitarian supply chain [40]. However, the literature on horizontal coordination in humanitarian supply chains is fairly limited. In this study, we mainly review the type of horizontal coordination that is at the same level of organizations within the chain.

With the scarcity of resources, there is competition between aid organizations at the same level. During the process of coordination, open interaction, such as information exchange and knowledge sharing, threatens the comparative advantage of organizations [41]. The extra costs of communication and negotiation also hinder horizontal coordination [13]. Schulz and Blecken investigated the main barriers to horizontal coordination in relief supply chains, such as insufficient resources, mistrust, protection of their competitive edge, and blindness to potential benefits [42]. In addition, the lead coordinator plays a pivotal role in ensuring the implementation of coordination [43]. The value created by coordination of the relief network is highlighted by Akhtar et al. [44]. Facing the great challenges brought by a rapid response and continuous supply, optimization of individual organizations has a limited impact on the utilization of resources. Strategic alliances or horizontal partnerships may be able to promote the sustainability of relief work because better and continuous coordination is conducive to improving agility [18,39]. In addition, social responsibility contributes to an external driving force for organizations to participate in the rescue network [45].

Horizontal coordination is well documented to achieve economies of scale and reduce the cost of individual aid agencies [13]. Most existing studies apply horizontal coordination to logistic service providers in the humanitarian supply chain $[46,47]$. The common method is to optimize vehicle capacity utilization and reduce the cost of noncore activities through the optimization of existing logistics processes and structures. Joint transportation and distribution management provide approaches for potential cost savings [48]. Lozano et al. found that horizontal coordination in humanitarian relief logistics benefits the profitability and improves the quality of services [49]. Toyasaki et al. reported that sustainable horizontal coordination mechanisms in inventory management could be realized based on the rapidly growing number of humanitarian organizations [50]. Fathalikhani et al. emphasized that partnership among humanitarian organizations is important to create innovation and improves the utilization of rare resources [51]. In this study, we try to deepen the horizontal coordination among NGOs.

\subsection{NGOs in Humanitarian Supply Chains}

To fulfill public service needs, NGOs have attracted considerable attention. In the humanitarian supply chain, NGOs operating to provide humanitarian relief undertake the tasks of postdisaster reconstruction and development. NGOs usually have comparative advantages in many aspects, such as providing medical treatment and assistance to affected people, and carry out recovery programs [52]. Based on their organization nature, NGOs in the humanitarian supply chain can be categorized into international NGOs and local NGOs. Generally, INGOs have better relief materials, professionalized 
capacity, and more experience in disaster relief than LNGOs because of their long history [53]. In addition, fully matured INGOs are more likely to have standardized management than LNGOs, so the quality of their services is guaranteed [54], whereas LNGOs tend to have closer ties with affected areas than INGOs [55]. There is no culture barrier when communicating with local communities and institutions for LNGOs. Local knowledge also allows LNGOs to quickly and accurately access specific disaster information [56-58]. Organizations endowed with different resources have different advantages in providing humanitarian aid. The performance of organizations is significantly different as well [59].

The differences in resource endowments provide a possibility for coordination. Yang noted that coordination between INGOs and LNGOs could benefit both sides [60]. However, the related research is limited. Most of the literature mainly concentrates on revealing the effectiveness of coordination between INGOs and LNGOs [61-64]. Resources-sharing is considered to be an important factor for successful coordination between INGOs and LNGOs, which can effectively enhance responsiveness [17], improve the quality of services, and reduce operational costs [65]. Tran and AbouAssi [66] emphasized that empowering an LNGO from an INGO is a useful method to develop coordination. In addition, coordination presents an opportunity for organizational learning. However, Adem et al. studied the case of Jordan and suggested that coordination between INGOs and LNGOs is not always encouraged [10]. Coordination between INGOs and LNGOs increases the risks of bypassing local authorities, damaging local NGO ecosystems [63], and causing mission drift for local players [65]. From organizational perspectives, coordination between INGOs and LNGOs encourages the dependency of local partners on the external resources of INGOs [62]. Therefore, a power imbalance is proposed during project implementation. The weaker parties have to meet the demands of the parties in a stronger position and may be marginalized by them. This issue can be further intensified by the absence of a governance board to manage partnerships effectively [52].

In addition, a few studies try to explain the forces associated with coordination. Lack of trust among NGOs is the main barrier to coordination [67]. The stability of partnerships can be destroyed by "free-riding" behavior [65]. Organizational conflict of interest is another factor leading to failure in coordination $[5,10]$. Competitive advantages of individual NGOs may lead to a loss in resource sharing [61]. Moreover, accompanied with problems such as a poor distribution of responsibilities and miscommunication between partners that result in high coordination costs, coordination could turn into failure [68-71]. In this study, we focus on the positive impact of coordination and attempt to analyze the influence factors of coordination mechanisms from dynamic and system perspectives.

\subsection{Research Gaps and Contributions}

In reviewing the literature, we found two main gaps. (1) Most of the literature [39,40,46-50] on humanitarian supply chain coordination focused on suppliers and logistics providers. As the main implementer of humanitarian activities, coordination mechanisms among NGOs are rarely mentioned. Although Fathalikhani et al. [52] proposed that NGOs should work together to manage disasters, they ignored the advantages of NGOs with different attributes in disaster relief, and an effective coordination mechanism was still lacking. (2) The literature $[53,55,58,60]$ on the key factors influencing coordination is commonly from static and qualitative perspectives. For instance, Adem et al. [10] conducted semistructured interviews of INGOs and LNGOs that had participated in providing humanitarian relief in Jordan to identify the key drivers and challenges in humanitarian supply chain coordination. They also did not consider the impact of the interaction among NGOs. However, the strategies of NGOs are often adjusted constantly according to changes in the environment and other NGOs' strategies. It is of great practical significance to analyze the influencing factors of coordination between INGOs and LNGOs in a dynamic and quantitative way.

In response to these gaps, this paper contributes to the literature regarding horizontal coordination between INGOs and LNGOs in humanitarian supply chains. First, we discuss the coordination mechanism motivated by the resource-sharing behavior between INGOs and LNGOs, which provides 
a new perspective for optimizing the sustainability of the relationship. Second, by combing the evolutionary game model with numerical simulation, we quantitatively analyze the key motivating and impeding factors of coordination and reflect the interaction of NGOs and the dynamic evolution path of the model under different scenarios. Although Azmat and Kummer [15] investigated the conflict of INGOs and LNGOs using the questionnaire survey method and empirically determined key factors for the relationship in relief operations, they only found the role of information sharing and ignored the impact of the behavior of other NGOs. Decision makers are not only affected by static factors, but also by interactions with other actors. Furthermore, the equilibrium conditions of the model provide feasible managerial implications for horizontal coordination in humanitarian supply chains.

\section{Model Formulation}

\subsection{Problem Description}

According to previous studies, both INGOs and LNGOs have their own advantages and disadvantages in disaster relief [46-48]. Horizontal coordination through resource-sharing can make up for the deficiencies of individual organizations and improve rescue efficiency. However, considering the uncertain surroundings and the conflicting interests, coordination is difficult to stabilize in the temporary network $[56,57]$. In this subsection, we consider a humanitarian supply chain consisting of multiple LNGOs in demand points and many INGOs as external supporters and formulate the behavior of NGOs in coordination as a decision-making game. As two parties in the game, both LNGOs and INGOs decide whether to share and how much to share their resources to achieve coordination with others. One player is randomly selected from LNGOs and INGOs each time to carry out the coordinated game. The information of the strategies adopted by other players is not available. Thus, judgment of benefits and costs is crucial to a player's decisions.

The benefits of INGOs and LNGOs can be illustrated as normal benefits, coordinated benefits, and opportunity benefits [6]. Due to their nonprofit characteristic, an improvement in the efficiency of disaster response can be treated as financial returns to NGOs [63,72]. Therefore, NGOs receive normal benefits from providing assistance in humanitarian relief. Coordinated benefits are produced through accessing complementary resources. Opportunity benefits refer to extra benefits from opportunistic behaviors of NGOs, such as the "free rider" $[65,66]$. The coordination strategy generates costs from interactive behavior [10]. Table 1 comprehensively overviews the benefits and costs of INGOs and LNGOs in the game model. With the deepening of relief activities, NGOs continuously adjust their strategies to optimize the benefits through learning and imitation.

Table 1. The benefits and costs of international nongovernment organizations (INGOs) and local nongovernment organizations (LNGOs).

\begin{tabular}{ccc}
\hline Terms & INGO & LNGO \\
\hline Normal benefits & The improvement of efficiency in relief supply \\
[43,72]; & $\begin{array}{c}\text { The improvement of efficiency in relief supply } \\
{[43,72] ;}\end{array}$ \\
& $\begin{array}{c}\text { Disaster information (e.g., affected location, } \\
\text { reasonable assessment of the number of casualties, } \\
\text { the extent of the humanitarian needs) [9,73]; }\end{array}$ & Expertise of disaster relief [54,61]; \\
\cline { 2 - 3 } Coordinated benefits & Legitimacy and social position [74]; & Channels to fund-raising [75] \\
\cline { 2 - 3 } & Reduction of inventory risk [13,61]; & Strategic-based help [76] \\
\cline { 2 - 3 } & "Free rider" behavior [65,68]; & $\begin{array}{c}\text { Improvement on the capacity of continuous } \\
\text { replenishment [71,76]. }\end{array}$ \\
\hline Opportunity benefits & $\begin{array}{c}\text { "Free rider" behavior [65,68]; } \\
\text { attend coordination meeting, negotiate a contract } \\
{[13,68] .}\end{array}$ & $\begin{array}{c}\text { Interactive behavior (e.g., understand each, attend } \\
\text { coordination meeting, negotiate a contract [13,68]. }\end{array}$ \\
\hline
\end{tabular}

\subsection{Assumptions and Variables}

According to evolutionary game theory, the following model assumptions are made: 
Assumption 1: INGOs and LNGOs in the humanitarian relief network are bounded rationality, which is the difference between complete rationality and complete irrationality.

Assumption 2: NGOs in humanitarian relief networks have the ability to learn to imitate and choose their own strategies. Since the information is incomplete, each party constantly adjusts their decisions based on the latest changes in other parties' strategies.

Assumption 3: NGOs have a strategy set $S=$ (coordination, non coordination). Those that adopt the "coordination" strategy are willing to share resources with others. We assume that both tangible resources (e.g., funds, materials, equipment) and intangible resources (e.g., information, knowledge, expertise, experience) can be managed and shared, so the strategic benefits of an NGO are measurable and assessable [65,75].

Assumption 4: NGOs with a "coordination" strategy have a "free-rider" risk. That is, the other party gains the external resources but is unwilling to share their own resources.

To show the benefits of NGOs under different strategies clearly, our model includes a number of variables, which are assumed to be being real numbers and have non-negative values. We define these variables below. The relevant notations and definitions are listed in Table 2.

Table 2. Notations and definitions.

\begin{tabular}{cc}
\hline Symbols & Descriptions \\
\hline$\pi_{i}$ & Normal benefits of INGO \\
$\pi_{l}$ & Normal benefits of LNGO \\
$R_{i}$ & The amount of sharable resources from INGO \\
$R_{l}$ & The amount of sharable resources from LNGO \\
$\lambda_{i}$ & Coordinated benefits coefficient of resources sharing of INGO \\
$\lambda_{l}$ & Coordinated benefits coefficient of resources sharing of LNGO \\
$\rho_{i}$ & Opportunity benefits coefficient of INGO \\
$\rho_{l}$ & Opportunity benefits coefficient of LNGO \\
$C_{i}$ & Coordinated costs of INGO \\
$C_{l}$ & Coordinated costs of LNGO \\
$x$ & the initial probability of INGO choosing coordination strategy \\
$y$ & the initial probability of LNGO choosing coordination strategy \\
\hline
\end{tabular}

\subsection{Model Framework}

Based on the above description, we can obtain the evolutionary game payoff matrix of the humanitarian relief network, as shown in Table 3.

Table 3. Payoff matrix of stakeholders.

\begin{tabular}{|c|c|c|c|}
\hline & & \multicolumn{2}{|c|}{ LNGO } \\
\hline & & Coordination $(y)$ & Non-Coordination $(1-y)$ \\
\hline INGO & $\begin{array}{c}\operatorname{coordination}(x) \\
\text { non coordination }(1-x)\end{array}$ & $\begin{array}{c}\pi_{i}+\lambda_{i} \mathrm{R}_{l}-\mathrm{C}_{i} \\
\pi_{l}+\lambda_{l} \mathrm{R}_{i}-\mathrm{C}_{l} \\
\pi_{i}+\rho_{i} \mathrm{R}_{l} \\
\pi_{l}-\mathrm{C}_{l}\end{array}$ & $\begin{array}{c}\pi_{i}-\mathrm{C}_{i} \\
\pi_{l}+\rho_{l} \mathrm{R}_{i} \\
\pi_{i} \\
\pi_{l}\end{array}$ \\
\hline
\end{tabular}

For INGOs, the expected benefits that adopt a "coordination" strategy are:

$$
U_{1}^{x}=\mathrm{y}\left(\pi_{i}+\lambda_{i} \mathrm{R}_{l}-\mathrm{C}_{i}\right)+(1-y)\left(\pi_{i}-\mathrm{C}_{i}\right)=\pi_{i}-\mathrm{C}_{i}+\mathrm{y} \lambda_{i} \mathrm{R}_{l}
$$

The expected benefits that adopt a "noncoordination" strategy are:

$$
U_{1}^{1-x}=\mathrm{y}\left(\pi_{i}+\rho_{i} \mathrm{R}_{l}\right)+(1-y) \pi_{i}=\pi_{i}+\mathrm{y} \rho_{i} \mathrm{R}_{l}
$$


Therefore, the average benefits of INGOs under the mixed strategies can be expressed by:

$$
\overline{U_{1}}=x * U_{1}^{x}+(1-x) * U_{1}^{1-x}=\pi_{i}+\mathrm{y} \rho_{i} \mathrm{R}_{l}-x \mathrm{C}_{i}+x \mathrm{y}\left(\lambda_{i}-\rho_{i}\right) \mathrm{R}_{l}
$$

According to EGT, if the expected benefits of one INGO adopting the "coordination" strategy are higher than the average expected benefits of all INGOs, the rest will imitate it in the next decision phase. The variation rate of the INGO's strategy can be described by a differential equation. Therefore, the replication dynamics equation of an INGO adopting the "coordination" strategy is:

$$
\mathrm{F}(x)=\frac{d x}{d t}=x\left(U_{1}^{x}-\overline{U_{1}}\right)=x(1-x)\left[\mathrm{y}\left(\lambda_{i}-\rho_{i}\right) \mathrm{R}_{l}-\mathrm{C}_{i}\right]
$$

When $\mathrm{F}(\mathrm{x})<0$, the probability $\mathrm{x}$ of an INGO choosing the "coordination" strategy will evolve to 0 . On the contrary, $\mathrm{F}(\mathrm{x})>0$ indicates that $\mathrm{x}$ will evolve to 1 over time.

Similarly, the LNGO's expected benefits of each strategy and the average benefits under the mixed strategies can be denoted as follows:

$$
\begin{gathered}
U_{2}^{y}=x\left(\pi_{l}+\lambda_{l} \mathrm{R}_{i}-\mathrm{C}_{l}\right)+(1-x)\left(\pi_{l}-\mathrm{C}_{l}\right)=\pi_{l}-\mathrm{C}_{l}+x \lambda_{l} \mathrm{R}_{i} \\
U_{2}^{1-y}=\mathrm{x}\left(\pi_{l}+\rho_{l} \mathrm{R}_{i}\right)+(1-x) \pi_{l}=\pi_{l}+x \rho_{l} \mathrm{R}_{i} \\
\overline{U_{2}}=y * U_{2}^{y}+(1-y) * U_{2}^{1-y}=\pi_{l}+x \rho_{l} \mathrm{R}_{i}-y \mathrm{C}_{l}+x\left(\lambda_{l}-\rho_{l}\right) \mathrm{R}_{i}
\end{gathered}
$$

The replication dynamics equation of a LNGO adopting the "coordination" strategy is:

$$
\mathrm{F}(\mathrm{y})=\frac{d y}{d t}=y\left(U_{2}^{y}-\overline{U_{2}}\right)=y(1-y)\left[x\left(\lambda_{l}-\rho_{l}\right) \mathrm{R}_{i}-\mathrm{C}_{l}\right]
$$

\section{Model analysis}

\subsection{Replicator Dynamics Analysis}

(1) Analysis of the replicator dynamics of the INGO's strategy

By solving $\mathrm{F}(x)=0$, we can obtain equilibrium points as $x_{1}=0$ and $x_{2}=1$. Based on EGT, the evolutionary stability state (ESS) of the INGO should satisfy $\mathrm{F}^{\prime}(x)<0$. We take the derivative of $\mathrm{F}(x)$ with respect to $x$ and obtain the following equation:

$$
\mathrm{F}^{\prime}(x)=(1-2 x)\left[\mathrm{y}\left(\lambda_{i}-\rho_{i}\right) \mathrm{R}_{l}-\mathrm{C}_{i}\right]
$$

Considering the value of $y$, we can divide the following analysis into three scenarios.

In scenario (1): if $y<\frac{C_{i}}{\left(\lambda_{1}-\rho_{1}\right) \mathrm{R}_{2}}$, then we can deduce that $\mathrm{F}^{\prime}(0)<0$ and $\mathrm{F}^{\prime}(1)>0$. Therefore, $x_{1}=0$ is the ESS, which means that an INGO with bounded rationality always chooses the "noncoordination" strategy. Even if the initial state is $x=1$, it will evolve to $x=0$ and stay there.

In scenario (2): if $y>\frac{C_{i}}{\left(\lambda_{1}-\rho_{1}\right) R_{2}}$, then $F^{\prime}(0)>0$ and $F^{\prime}(1)<0$. Therefore, $x_{2}=1$ is the ESS. That is, the behavior of the INGO tends towards "coordination" and reaches stability eventually.

In scenario (3): if $\mathrm{y}=\frac{\mathrm{C}_{i}}{\left(\lambda_{1}-\rho_{1}\right) \mathrm{R}_{2}}$, then $\mathrm{F}^{\prime}(x)=0$, which means that all $x$ are in an evolutionarily stable state. The initial strategy does not change over time. The replicator dynamics phase diagrams of the INGO are shown in Figure 1. 


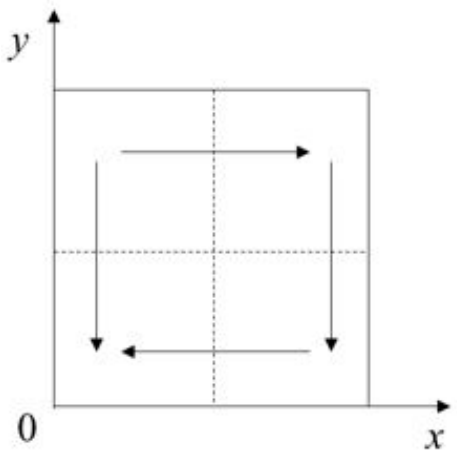

(a)

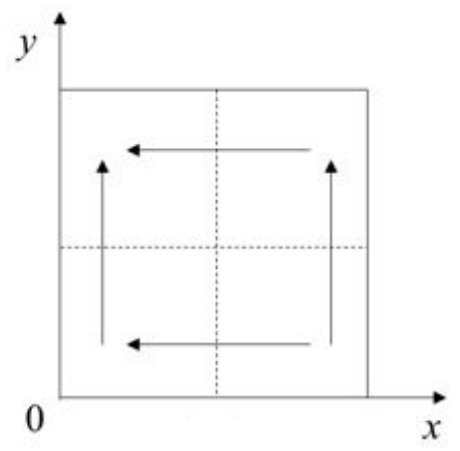

(b)

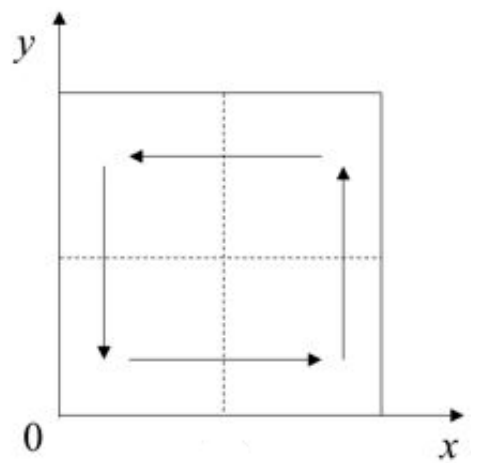

(c)

Figure 1. Replicator dynamics phase diagrams of INGO. (a) The replicator dynamics phase diagrams for the INGO under scenario (1). (b) The replicator dynamics phase diagrams for the INGO under scenario (2). (c) The replicator dynamics phase diagrams for the INGO under scenario (3).

(2) Analysis of the replicator dynamics of the LNGO's strategy

For LNGOs, we take the derivative of $\mathrm{F}(y)$ with respect to $y$ and obtain the following equation:

$$
\mathrm{F}^{\prime}(y)=(1-2 y)\left[x\left(\lambda_{l}-\rho_{l}\right) \mathrm{R}_{i}-\mathrm{C}_{l}\right]
$$

Similar to the above analysis method, $y_{1}=0$ and $y_{2}=1$ are equilibrium points. Thus, we have three scenarios based on the value of $x$.

In scenario (1): if $x<\frac{C_{l}}{\left(\lambda_{l}-\rho_{l}\right) R_{i}}$, then $F^{\prime}(0)<0$ and $F^{\prime}(1)>0$. Therefore, $y_{1}=0$ is the ESS, which means the LNGO with bounded rationality always chooses the "noncoordination" strategy regardless of the initial state.

In scenario (2): if $x>\frac{C_{l}}{\left(\lambda_{l}-\rho_{l}\right) R_{i}}$, then $F^{\prime}(0)>0$ and $F^{\prime}(1)<0$. Thus, the ESS is $y_{2}=1$. All $y$ will evolve to 0 .

In scenario (3): if $\mathrm{x}=\frac{\mathrm{C}_{l}}{\left(\lambda_{l}-\rho_{l}\right) \mathrm{R}_{i}}$, then $\mathrm{F}^{\prime}(y)=0$, which means that any $\mathrm{y}$ is an evolutionary stable state. The replicator dynamics phase diagrams for the LNGO are shown in Figure 2.

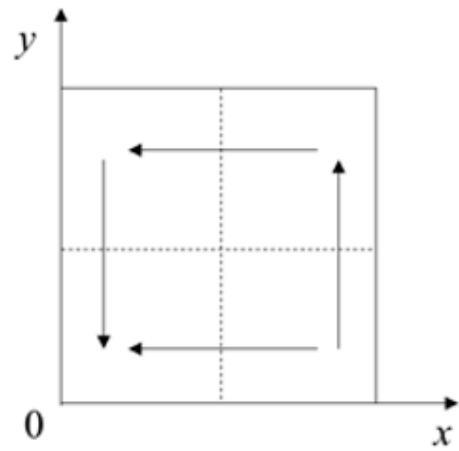

(a)

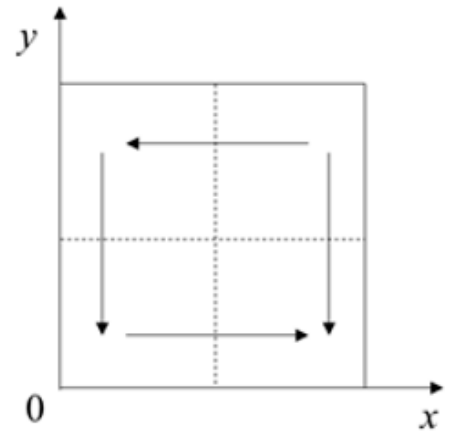

(b)

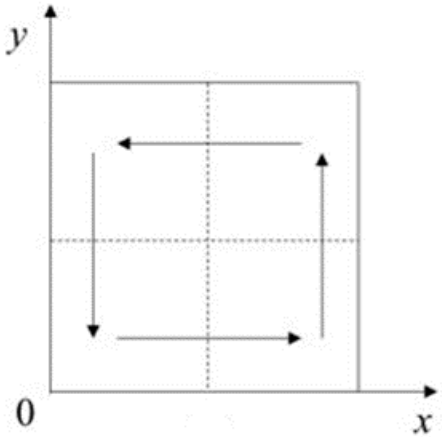

(c)

Figure 2. Replicator dynamics phase diagrams of LNGO. (a) The replicator dynamics phase diagrams for the LNGO under scenario (1). (b) The replicator dynamics phase diagrams for the LNGO under scenario (2). (c) The replicator dynamics phase diagrams for the LNGO under scenario (3).

From the above analysis, we can see that the key factors influencing the behavior of either player in this evolutionary game model are coordinated benefits and opportunity benefits, as well as the other party's strategies. To understand the interaction mechanism, the evolutionary stability strategy of the model is further explored. 


\subsection{Stability of the Evolutionary Strategies Analysis}

By setting Equations (4) and (8) to 0, we can obtain five groups of equilibrium points, $(1,1),(1,0),(0,1),(0,0),\left(\frac{\mathrm{C}_{l}}{\left(\lambda_{l}-\rho_{l}\right) \mathrm{R}_{i}}, \frac{\mathrm{C}_{i}}{\left(\lambda_{1}-\rho_{1}\right) \mathrm{R}_{2}}\right) . \quad$ Following Friedman's equilibrium theory [77], we analyze the local stability of the stable points by identifying the determinant (Det) and trace (Tr) sign of the Jacobian matrix (J). The Jacobian matrix of our model is as follows:

$$
\begin{aligned}
\mathrm{J} & =\left[\begin{array}{cc}
\frac{\partial F(x)}{\partial x} & \frac{\partial F(x)}{\partial y} \\
\frac{\partial F(y)}{\partial x} & \frac{\partial F(y)}{\partial y}
\end{array}\right] \\
& =\left[\begin{array}{cc}
(1-2 x)\left[\mathrm{y}\left(\lambda_{i}-\rho_{i}\right) \mathrm{R}_{l}-\mathrm{C}_{i}\right] & x(1-x)\left(\lambda_{i}-\rho_{i}\right) \mathrm{R}_{l} \\
y(1-y)\left(\lambda_{l}-\rho_{l}\right) \mathrm{R}_{i} & (1-2 y)\left[x\left(\lambda_{l}-\rho_{l}\right) \mathrm{R}_{i}-\mathrm{C}_{l}\right]
\end{array}\right]
\end{aligned}
$$

Thus, the determinant (Det) and trace ( $T r$ ) can be calculated as follows:

$$
\begin{gathered}
\operatorname{Det} J=(1-2 x)\left[\mathrm{y}\left(\lambda_{i}-\rho_{i}\right) \mathrm{R}_{l}-\mathrm{C}_{i}\right] *(1-2 y)\left[x\left(\lambda_{l}-\rho_{l}\right) \mathrm{R}_{i}-\mathrm{C}_{l}\right] \\
-x(1-x)\left(\lambda_{i}-\rho_{i}\right) \mathrm{R}_{l} * y(1-y)\left(\lambda_{l}-\rho_{l}\right) \mathrm{R}_{i}
\end{gathered}
$$

To determine the stability of the five equilibrium points, we solve Equations (12) and (13) under four conditions. The corresponding equilibrium results of the model are given in Tables 4-7.

Table 4. Equilibrium stability analysis under Condition 1.

\begin{tabular}{ccccc}
\hline Condition 1 & Equilibrium Points & DerJ & TrJ & State \\
\hline$(1,1)$ & $(0,1)$ & +1 & $-{ }^{2}$ & ESS \\
$\left(\lambda_{i}-\rho_{i}\right) \mathrm{R}_{l}-\mathrm{C}_{i}>0 ;$ & $(1,0)$ & + & + & Unstable \\
$\left(\lambda_{l}-\rho_{l}\right) \mathrm{R}_{i}-\mathrm{C}_{l}>0$ & $(0,0)$ & + & + & Unstable \\
& $\left(\frac{\mathrm{C}_{l}}{\left(\lambda_{l}-\rho_{l}\right) \mathrm{R}_{i}}, \frac{\mathrm{C}_{i}}{\left(\lambda_{i}-\rho_{i}\right) \mathrm{R}_{l}}\right)$ & $*^{3}$ & $*$ & ESS \\
& & & - & Unstable \\
\hline
\end{tabular}

Note: ${ }^{1 ~ "+" m e a n s ~ t h e ~ v a l u e ~ i s ~ g r e a t e r ~ t h a n ~} 0,{ }^{2}$ " - "means the value is less than $0,{ }^{3}$ " $*$ "means the value is uncertain.

Table 5. Equilibrium stability analysis under Condition 2.

\begin{tabular}{ccccc}
\hline Condition 2 & Equilibrium Points & DerJ & TrJ & State \\
\hline$(1,1)$ & $(0,1)$ & +1 & + & Unstable \\
$\left(\lambda_{i}-\rho_{i}\right) \mathrm{R}_{l}-\mathrm{C}_{i}<0 ;$ & $(1,0)$ & $-{ }^{2}$ & $* 3$ & Saddle point \\
$\left(\lambda_{l}-\rho_{l}\right) \mathrm{R}_{i}-\mathrm{C}_{l}<0$ & $(0,0)$ & - & $*$ & Saddle point \\
& $\left(\frac{\mathrm{C}_{l}}{\left(\lambda_{l}-\rho_{l}\right) \mathrm{R}_{i}}, \frac{\mathrm{C}_{i}}{\left(\lambda_{i}-\rho_{i}\right) \mathrm{R}_{l}}\right)$ & $*$ & $*$ & ESS \\
& & + & - & Unstable \\
\hline
\end{tabular}

Note: ${ }^{1 ~ "+}$ "means the value is greater than $0,{ }^{2}$ " - "means the value is less than $0,{ }^{3}$ " $*$ "means the value is uncertain.

Table 6. Equilibrium stability analysis under Condition 3.

\begin{tabular}{ccccc}
\hline Condition 3 & Equilibrium Points & DerJ & TrJ & State \\
\hline$(1,1)$ & $(0,1)$ & -1 & $* 3$ & Saddle point \\
$\left(\lambda_{i}-\rho_{i}\right) \mathrm{R}_{l}-\mathrm{C}_{i}<0 ;$ & $(1,0)$ & - & $*$ & Saddle point \\
$\left(\lambda_{l}-\rho_{l}\right) \mathrm{R}_{i}-\mathrm{C}_{l}>0$ & $(0,0)$ & +2 & + & Unstable \\
& $\left(\frac{\mathrm{C}_{l}}{\left(\lambda_{l}-\rho_{l}\right) \mathrm{R}_{i}}, \frac{\mathrm{C}_{i}}{\left(\lambda_{i}-\rho_{i}\right) \mathrm{R}_{l}}\right)$ & $*$ & $*$ & ESS \\
& & + & Unstable \\
\hline
\end{tabular}

Note: ${ }^{1}$ " - "means the value is less than $0,{ }^{2}$ " + "means the value is greater than $0,{ }^{3}$ " $*$ "means the value is uncertain. 
Table 7. Equilibrium stability analysis under Condition 4.

\begin{tabular}{ccccc}
\hline Condition 4 & Equilibrium Points & DerJ & TrJ & State \\
\hline$(1,1)$ & $(0,1)$ & -1 & $* 3$ & Saddle point \\
$\left(\lambda_{i}-\rho_{i}\right) \mathrm{R}_{l}-\mathrm{C}_{i}>0 ;$ & $(1,0)$ & $+{ }^{2}$ & + & Unstable \\
$\left(\lambda_{l}-\rho_{l}\right) \mathrm{R}_{i}-\mathrm{C}_{l}<0$ & $(0,0)$ & - & $*$ & Saddle point \\
& $\left(\frac{\mathrm{C}_{l}}{\left(\lambda_{l}-\rho_{l}\right) \mathrm{R}_{i}}, \frac{\mathrm{C}_{i}}{\left(\lambda_{i}-\rho_{i}\right) \mathrm{R}_{l}}\right)$ & $*$ & $*$ & ESS \\
& & & Unstable
\end{tabular}

Note: ${ }^{1 ~ "-" m e a n s ~ t h e ~ v a l u e ~ i s ~ l e s s ~ t h a n ~} 0,{ }^{2}$ " + "means the value is greater than $0,{ }^{3}$ " $*$ "means the value is uncertain.

Under condition 1: the benefits the INGO and LNGO gained from coordination are higher than the coordination costs. By continuously learning and improving, both players would find out that coordination is a better strategy than others. Thus, the system converges to point $(1,1)$, which shows that the strategy set (coordination, coordination) is a stable result.

Under condition 2: the benefits the INGO and LNGO gained from coordination are less than the coordination costs. Choosing the noncoordination strategy can provide players more benefits. The system evolves to point $(0,0)$ over time.

Under condition 3: the benefits of adopting a coordination strategy are much greater for the LNGO than when it chooses noncoordination. However, for the INGO, the result is the opposite. Similar to the discussion of Condition 2, the model would be stable at point $(0,0)$. Both the INGO and LNGO choose the noncoordination strategy eventually.

Under condition 4: Contrary to condition 3, only the INGO can obtain benefits from coordination. Therefore, the probability of the LNGO adopting a coordination strategy will gradually reduce to 0 , which decreases the coordination desire of the INGO. Finally, point $(0,0)$ is the ESS.

According to the above analysis of the four conditions, we can conclude that only when both the INGO and LNGO are willing to coordinate with the other can the coordination strategy be stable. If one of them is unwilling to coordinate, the partnership will not be achieved. The coordination desire can be motivated by their judgment of benefits, which include coordinated benefits and opportunity benefits, but it can be weakened by coordinated costs. To determine the incentive effect of variables and the evolutionary path of players intuitively, we conduct a numerical simulation experiment in the next section.

\section{Numerical Simulation and Discussion}

\subsection{Case and Parameters Setting}

Since December 2019, COVID-19 has infected millions of people around the world. This emergent public health event has had a serious impact on people's lives. For example, the Wuhan government suspended the urban transportation system, closed all places of public entertainment and stopped the operation of businesses to keep people at home for three months. This event may cost 300-500 billion yuan in Chinese GDP in 2020. When the event occurred, a large group of NGOs quickly formed the China NGO Consortium for 2019-ncov (cnc-2019ncov) for humanitarian assistance. The main work of this consortium included (1) conveying specific action information, including action time, place, personnel, specific content, support object, etc.; (2) sharing expertise and experience and providing feedback for the rescue progress; (3) supporting activities of local organizations, such as managing volunteers, assessing the demand of affected people, and helping to formulate rescue plans and relevant capacity building; and (4) integrating and allocating social resources according to the demand assessment. With the help of CNC-2019nCOV, local NGOs and communities provided various services to residents affected by COVID-19, which involved spreading scientific knowledge and providing information consultation, psychological support, emotional counseling, service coordination, resource links, and so on. Meanwhile, local organizations shared their information about affected areas with CNC-2019nCOV. 
In this event, CNC-2019nCOV and local organizations worked together and formed an efficient organizational coordination network.

In this case, we can regard CNC-2019nCOV as an INGO. Local nonprofit organizations, communities, and volunteer organizations are the corresponding LNGOs. From the coordination, the LNGO obtained professional knowledge and improved the rescue ability, as well as improved the operation efficiency of organizations. The INGO can acquire information for demand and rescue progress quickly and accurately, which accelerates the demand response time and increases the service quality. However, the coordination benefits in this case are intangible and lack exact data. Therefore, we assigned parameters by referring to Li's study of humanitarian organizational coordination [6]. Since this work concentrated on the sensitivity of player behavior to parameters in the model, the randomness of the parameter assignment does not affect the simulation results [78]. To examine the impact of the initial behavior of players, we use a probability higher than 0.5 to indicate a high coordination desire. Conversely, a probability less than 0.5 indicates a low coordination desire [22]. By using the MATLAB software (version R2018, The WorkMaths, Natick, MA, USA), the evolutionary path of players and the influence of key factors can be observed intuitively. The initial values for the relevant parameters are shown in Table 8.

Table 8. The values of parameters.

\begin{tabular}{ccccccccc}
\hline Parameter & $\boldsymbol{R}_{\boldsymbol{i}}$ & $\boldsymbol{R}_{\boldsymbol{l}}$ & $\boldsymbol{C}_{\boldsymbol{i}}$ & $\boldsymbol{C}_{\boldsymbol{l}}$ & $\boldsymbol{\lambda}_{\boldsymbol{i}}$ & $\lambda_{l}$ & $\rho_{i}$ & $\rho_{\boldsymbol{l}}$ \\
\hline Value & 240 & 240 & 80 & 80 & 0.9 & 0.9 & 0.4 & 0.4 \\
\hline
\end{tabular}

\subsection{Sensitivity Analysis of Parameters}

\subsubsection{Impact of Initial Strategies on Coordination}

Figure 3 shows the evolutionary path of players with initial strategies set as $(0.3,0.2),(0.8,0.9),(0.3,0.9)$ and $(0.8,0.2)$. Under four different situations, the influence of the behavior change of players on the evolutionary relationship is explored.

From the simulation results, we can see that coordination can be achieved when at least one player has a strong willingness to coordinate. If both parties tend to choose a "noncoordination" strategy, the system converges to $(0,0)$ directly, therefore promoting mutual trust and encouraging NGOs' willingness in the early stage will be conducive to improve the horizontal coordination in the humanitarian supply chain.

\subsubsection{Impact of $\mathrm{R}$ on the Coordination}

To reflect the impact of the value of sharable resources, we change the value of $\mathrm{R}_{l}$ from 160 to 320 and present the results in Figure 4. In the case of an initial probability of $x=0.5, y=0.5$ [71], we can see that as the degree of the value of sharable resources decreases, and both parties will choose a "noncoordination" strategy eventually. Under this situation, resources-sharing between the INGO and LNGO is inequitable, which makes rational organization with more sharable resources lack coordination motivation.

As the value of $\mathrm{R}_{l}$ changes, the model has a different stable state. When the sharable resources of LNGO are relatively high, INGO evolves to 1 faster. The coordination behavior of the LNGO can be encouraged by the high coordination willingness of the INGO. However, the LNGO holding less sharable resources will impede the coordination. Both the INGO and LNGO tend to choose "noncoordination," and the model will finally be stable at $(0,0)$. 


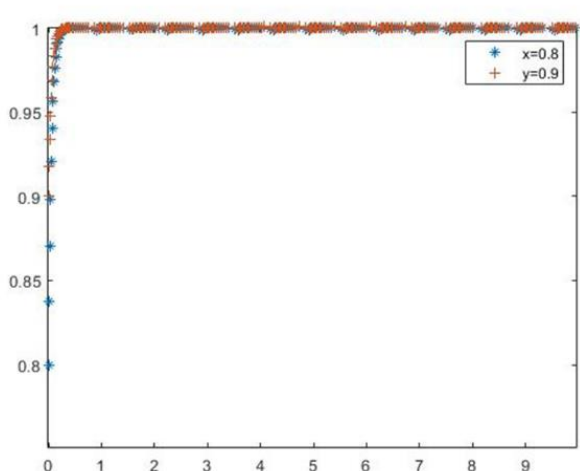

(a)

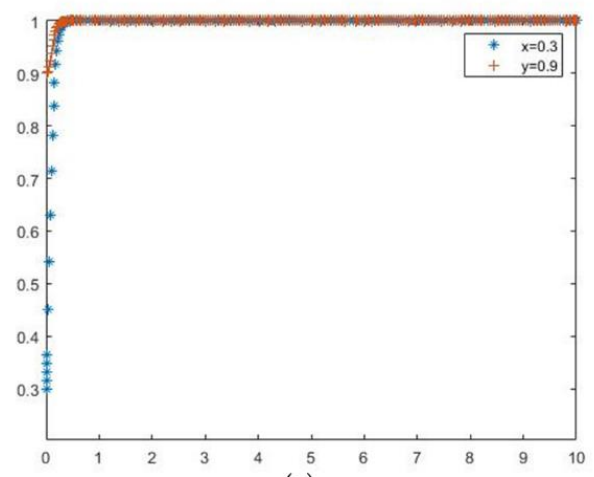

(c)

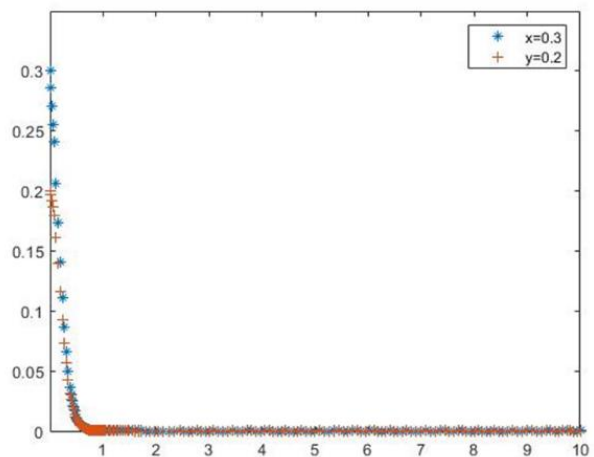

(b)



(d)

Figure 3. Evolutionary path diagrams under different initial strategy. (a) Game players' initial strategy probabilities $(\mathrm{x}, \mathrm{y})$ were set as $(0.8,0.9)$. (b) Game players' initial strategy probabilities $(\mathrm{x}, \mathrm{y})$ were set as $(0.3,0.2)$. (c) Game players' initial strategy probabilities $(x, y)$ were set as $(0.3,0.9)$. (d) Game players' initial strategy probabilities $(\mathrm{x}, \mathrm{y})$ were set as $(0.8,0.2)$.

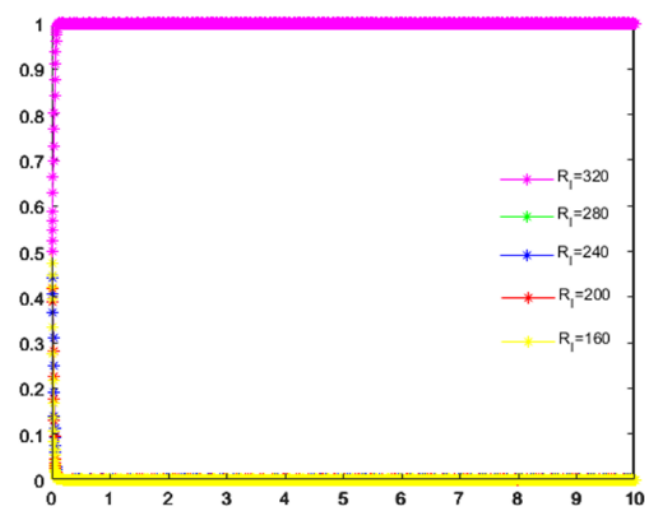

(a)

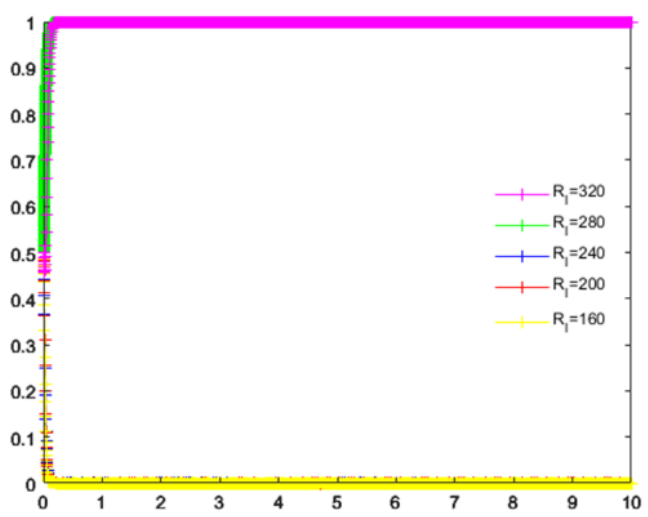

(b)

Figure 4. The impact of $\mathrm{R}_{l}$ on evolutionary results. The evolutionary path diagrams of INGO (a) and the evolutionary path diagrams of LNGO (b).

\subsubsection{Impact of $\mathrm{C}$ on Coordination}

Coordination cost is another main factor affecting the behavior of players. A high coordination cost has an impact on the expected benefits. As shown in Figure 5, we simulate the evolutionary trend of INGO and LNGO at different values of $C_{i}$. Maintaining the initial probability of $x=0.5, y=0.5$, we change the value of $C_{i}$ from 120 to 40 . When $C_{i}$ is higher than 40 , "noncoordination" is the final choice of both sides. If $C_{i}$ decreased to 40 , both INGO and LNGO will choose a "coordination" strategy, and the speed of the INGO evolving to 1 is faster. In addition, when $C_{i}=60$, INGO has a coordination 
willingness at an early stage, and the probability of INGO increases for a short time but converge to 0 eventually. Correspondingly, the probability of LNGO gradually decreases to 0 .

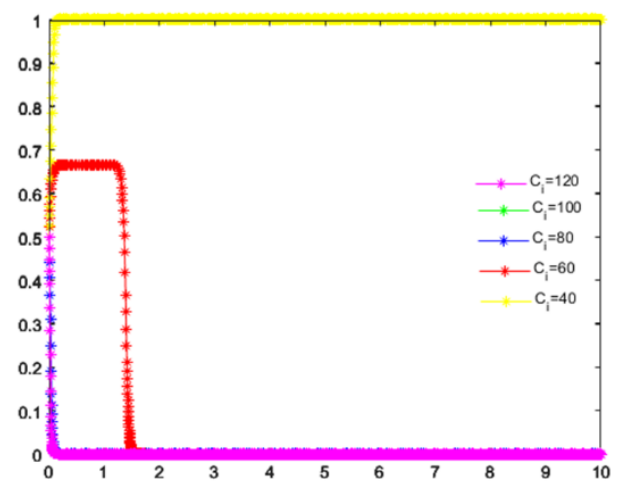

(a)

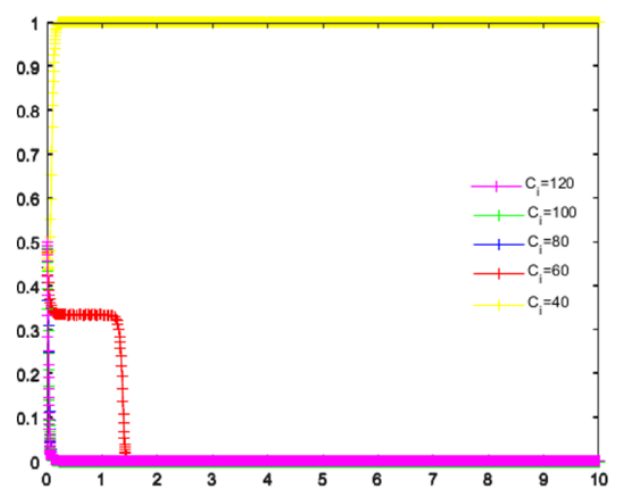

(b)

Figure 5. The impact of $C_{i}$ on evolutionary results. The evolutionary path diagrams of INGO (a) and the evolutionary path diagrams of LNGO (b).

\subsubsection{Impact of Benefits Coefficients on Coordination}

According to the analysis in Section 4, the coordinated benefits coefficient and the opportunity benefits coefficient have opposite effects on the behavior of individual NGOs. A high coordinated benefits coefficient means that the organization can receive more benefits from interactions, which is related to the organizational capability. Conversely, a high opportunity benefits coefficient stimulates "free-rider" behavior. To identify the relationship between the evolutionary trend of the system and the benefits coefficient, we take the coordinated benefits coefficient of INGO as an example and set $\lambda_{i}$ from 0.8 to 1 . The same effect can be achieved by improving the opportunity benefits coefficient from 0.3 to 0.5 . As shown in Figure 6, the initial probabilities are $x=0.5, y=0.5$. Only when $\lambda_{i}=1$ can the model be stable at point $(1,1)$. A lower level of coordinated benefits coefficient restricts the INGO gain from resources-sharing. In this situation, the INGO has little desire to coordinate with others, which accelerates the evolutionary speed of the LNGO toward "noncoordination." If the opportunity benefits coefficient is relatively high, the consequence of the game will not change.



(a)

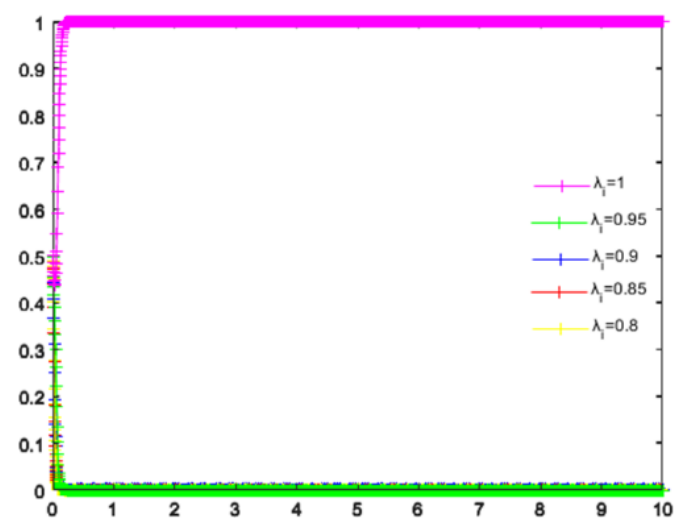

(b)

Figure 6. The impact of $\lambda_{i}$ on evolutionary results. The evolutionary path diagrams of INGO (a) and the evolutionary path diagrams of LNGO (b).

\subsection{Discussion}

In relief operations with high uncertainty characteristics, resources-sharing is a critical mechanism for coordination realization $[17,74]$. The extent of sharing depends on the demand and cost. Therefore, 
barriers to resources-sharing also hinder coordination. Based on the assumption of bounded rationality, this paper analyses the evolutionary game process of coordination between INGO and LNGO at the response phase through resources-sharing. In the case of COVID-19 proposed by us, this paper proposed a coordination mode of INGOs sharing knowledge and rescue skills and LNGOs sharing disaster information and demand based on the organizational character. However, according to different types of disasters and relief environment, the demands for resources vary. For instance, when assisting the Lebanese after a war, since the LNGO has more power, the coordination can empower the INGO to participate in local activities and derive its legitimacy. At the same time, the LNGO can obtain the INGO's donation resources and international network to build capacity [66]. In the case of the Ya'an earthquake, humanitarian organizations, including INGOs and LNGOs, coordinated their activities by forming an alliance and establishing information and knowledge sharing mechanisms from formal and informal channels [40]. The research on the Chennai flood in 2015 noted the necessity of sharing and understanding information between INGOs and local volunteer organizations to achieve coordination [19]. According to Spiegel et al. [79], NGOs and local communities established a partnership through information sharing, human resource sharing, and risk transfer when responding to the epidemic in Yemen. Thus, we can conclude that although there are various modes of coordination, intangible and tangible resources-sharing is the main path of coordination in humanitarian organizations.

Different from other microscopic studies of the drivers and advantages of coordination, this study tries to explain what the optimal decision is and how the coordination mechanism evolves in a dynamic perspective. We are seeking the general process or phenomena of interactions between INGOs and LNGOs, but not the relations in a specific setting. Our numerical simulation experiment captured the behavior changes of INGOs and LNGOs and validated the impact of key factors effectively. The computational results show that the amount of sharable resources and coordinated benefits coefficients have a positive impact on coordination. The coordination costs and opportunity benefits coefficient have the opposite effect. In addition, the willingness to coordinate NGOs can influence the other's behavior and moderate the evolution path of the model to some extent.

\subsection{Management Implications}

First, our study helps NGOs understand the coordination mechanism based on resources-sharing, which can be an effective method to promote the sustainable development of humanitarian activities by avoiding resources contention and generating extra benefits. Similarly, Pazirandeh and Maghsoudi [17] showed that the sharing of complementary resources plays a significant role in improving the coordination performance between INGOs and LNGOs. By increasing the expected benefits of NGOs, sharable resources can greatly increase NGOs' enthusiasm to participate in coordination. Previous studies suggest that resource scarcity is a common problem in humanitarian organizations $[13,63]$. It may not be wise to obtain some necessary resources and only rely on their own efforts by investing too much in internal resources blindly. Meanwhile, managers should make efforts to improve the capacity of organizational learning and resources utilization to maximize the value of shared resources, which have a positive impact on the selection of coordination strategy. Our evolutionary model highlights the dynamic path of each player, which gives managers theoretical guidance to adjust the optimal strategy and maximize their benefits.

Second, the results remind NGOs to maintain an open mind and actively seek coordination because NGOs' willingness to coordinate can motivate each other and make the coordination easier to realize. As suggested by many scholars, external forces such as the appropriate macrocontrol measures adopted by the government can also inspire their willingness to coordinate [53,59]. The government functions of legislation and authorization play an important role in accomplishing the social missions of NGOs and establishing equilibrium in different industries [10]. Fathalikhani et al. [52] found that properly designed and planned responsibilities for humanitarian organizations by governments can lead to better decision-making and more coordinated management when dealing with time-sensitive 
situations. Moreover, the guidance of policies can promote swift trust among NGOs, which is conducive to form a long-term stable relationship [57]. For example, in the early stage of COVID-19 in Wuhan, the Red Cross Society of China Wuhan Branch, the Hubei Provincial Foundation for Youth Development and three other NGOs were designated as the local responsible organizations for receiving donations and distributing charitable resources by the government. These organizations were encouraged to coordinate with other NGOs and undertake a pivotal role in charity. Some temporary NGOs and communities also proactively seek out and establish coordination with mature NGOs possessing the qualification of public offerings. In addition, social media also has an impact on coordination between INGOs and LNGOs. According to Moshtari et al. [68], social media provide opportunities for the visibility of resources, activities, and procedures in humanitarian relief and gives technical support for information diffusion and enhances the communication among organizations [43].

Third, managers need to pay attention to reduce the influence of coordination costs and the risk of "free-riders." Complex management processes increase operational and coordination costs $[5,13]$. As noted by Agarwal et al. [11], optimizing organizational processes, reasonable division of labor, and clear responsibilities and rights are common methods to improve the internal efficiency of organizations and minimize management costs. Many examples show how communication failure, political values, and identity undermine the collective efforts in crisis [80]. Miscommunication between partners caused by culture and language barriers is the main problem, which seriously increases the coordination costs. Prasanna [58] proposed that organizational culture can be understood in routine activities that are largely unconscious and automatic. Therefore, Altay and Pal [74] supported that maintaining information exchange can elevate communication efficiency and eliminate misunderstanding. Adem et al. [10] provided a solution to replace the staff of international missions with local participants, who are more familiar with local culture and related policies. It is helpful to avoid unnecessary mistakes and reduce costs. Azmat [15] also explained that hiring qualified professionals can make charitable organizations more rational. For instance, the Wuhan Red Cross outsourced the relief material inventory and transportation to a professional third-party logistics company. The response efficiency improved through a specialized management path. In addition, overcoming cultural conflicts and policy constraints is also helpful to reduce the coordinated costs [12,58].

\section{Conclusions and Future Research}

This study explores the coordination mechanism between INGOs and LNGOs in the humanitarian supply chain by applying evolutionary game theory. Based on the assumption of rational economic humans, interest conflicts existing in players can lead to the failure of horizontal coordination. Combined with previous studies, we discuss the impact of key factors and initial strategies on our dynamic model in a quantitative way. The results show that coordinated benefits can affect the behavior of players positively. However, opportunity benefits and coordinated costs hamper the partnership. In the meantime, each player's strategy can be changed by the reaction of others.

The contributions of our study mainly focus on two aspects. First, our analysis provides an effective method to enhance the capacity for the sustainable development of the humanitarian supply chain from the coordination perspective. We demonstrate that resources-sharing is the main motivation for coordination between INGOs and LNGOs. Organizations with complementary resources should achieve coordination to make relief activities more sustainable. In addition, horizontal coordination between INGOs and LNGOs prevents the competition for limited resources and avoids repetitive tasks. Second, our results highlight the interaction mechanism among players and calculate the optimal coordinated strategy in different conditions. The quantitative method also addresses the research gaps.

This study can be extended in several directions. First, through in-depth research in the future, we can explore more factors in the coordination mechanism. Multi-stakeholders, including an enterprise, donor, media and others, can be included in the coordination model. Second, the coordination models in different types of relief operations are also worthy of further investigation. We can also consider in the future an investigation regarding the intersections with the Green Public Procurement $[81,82]$ 
and Green Procurement in the private sector [83,84]. Furthermore, it is necessary to consider how to optimize resource utilization in the horizontal coordination framework.

Author Contributions: Conceptualization, F.C. and S.L.; methodology, F.C.; software, F.C.; validation, F.C. and S.L.; formal analysis, F.C.; writing—original draft preparation, F.C.; writing—review and editing, S.L. and A.A.; project administration, S.L. and A.A.; funding acquisition, S.L. and A.A. All authors have read and agreed to the published version of the manuscript.

Funding: This research was funded by the National Natural Science Foundation Council of China under Projects No. 71862035 and No. 71502159; the Yunnan Fundamental Research Project under grant No. 2019 FB085.

Conflicts of Interest: The authors declare no conflict of interest.

\section{References}

1. Banomyong, R.; Varadejsatitwong, P.; Oloruntoba, R. A systematic review of humanitarian operations, humanitarian logistics and humanitarian supply chain performance literature 2005 to 2016. Ann. Oper. Res. 2019, 283, 71-86. [CrossRef]

2. Galindo, G.; Batta, R. Review of recent developments in OR/MS research in disaster operations management. Eur. J. Oper. Res. 2013, 230, 201-211. [CrossRef]

3. Tacheva, Z.; Simpson, N. Social network analysis in humanitarian logistics research. J. Humanit. Logist. Supply Chain Manag. 2019, 9, 492-514. [CrossRef]

4. Dubey, R.; Luo, Z.; Gunasekaran, A.; Akter, S.; Hazen, B.T.; Douglas, M.A. Big data and predictive analytics in humanitarian supply chains. Int. J. Logist. Manag. 2018, 29, 485-512. [CrossRef]

5. Van Wassenhove, L.N. Humanitarian aid logistics: Supply chain management in high gear. J. Oper. Res. Soc. 2006, 57, 475-489. [CrossRef]

6. Li, C.; Zhang, F.; Cao, C.; Liu, Y.; Qu, T. Organizational coordination in sustainable humanitarian supply chain: An evolutionary game approach. J. Clean. Prod. 2019, 219, 291-303. [CrossRef]

7. Haavisto, I.; Kovács, G. Perspectives on sustainability in humanitarian supply chains. Dis. Prev. Manag. Int. J. 2014, 23, 610-631. [CrossRef]

8. Ibegbunam, I.; McGill, D. Health commodities management system: Priorities and challenges. J. Humanit. Logist. Supply Chain Manag. 2012, 2, 161-182. [CrossRef]

9. Khan, M.; Lee, H.; Bae, J. The role of transparency in humanitarian logistics. Sustainability 2019, 11, 2078. [CrossRef]

10. Adem, S.A.; Childerhouse, P.; Egbelakin, T.; Wang, B. Int.ernational and local NGO supply chain collaboration. J. Humanit. Logist. Supply Chain Manag. 2018, 8, 295-322. [CrossRef]

11. Agarwal, S.; Kant, R.; Shankar, R. Humanitarian supply chain management frameworks. Benchmarking Int. J. 2019, 26, 1749-1780. [CrossRef]

12. Dubey, R.; Gunasekaran, A.; Childe, S.J.; Roubaud, D.; Fosso Wamba, S.; Giannakis, M.; Foropon, C. Big data analytics and organizational culture as complements to swift trust and collaborative performance in the humanitarian supply chain. Int. J. Prod. Econ. 2019, 210, 120-136. [CrossRef]

13. Balcik, B.; Beamon, B.M.; Krejci, C.C.; Muramatsu, K.M.; Ramirez, M. Coordination in humanitarian relief chains: Practices, challenges and opportunities. Int. J. Prod. Econ. 2010, 126, 22-34. [CrossRef]

14. Sandwell, C. A qualitative study exploring the challenges of humanitarian organisations. J. Humanit. Logist. Supply Chain Manag. 2011, 1, 132-150. [CrossRef]

15. Azmat, M.; Kummer, S. Importance of key success factors for local and international NGOs in humanitarian supply chain. Sci. J. Logist. 2019, 15, 545-555. [CrossRef]

16. Reza Zanjirani Farahani, M.M.L.A. Mass casualty management in disaster scene: A systematic review of OR\&MS research in humanitarian operations. Eur. J. Oper. Res. 2020. [CrossRef]

17. Pazirandeh, A.; Maghsoudi, A. Improved coordination during disaster relief operations through sharing of resources. J. Oper. Res. Soc. 2017, 69, 1227-1241. [CrossRef]

18. Dubey, R.; Angappa, G. The sustainable humanitarian supply chain design: Agility, adaptability and alignment. Int. J. Logist. Res. Appl. 2016, 19, 62-82. [CrossRef]

19. John, L.; Gurumurthy, A.; Soni, G.; Jain, V. Modelling the inter-relationship between factors affecting coordination in a humanitarian supply chain: A case of Chennai flood relief. Ann. Oper. Res. 2019, 283, 1227-1258. [CrossRef] 
20. Hashemi Petrudi, S.H.; Tavana, M.; Abdi, M. A comprehensive framework for analyzing challenges in humanitarian supply chain management: A case study of the Iranian Red Crescent Society. Int. J. Disast. Risk Reduct. 2020, 42, 101340. [CrossRef]

21. Ji, P.; Ma, X.; Li, G. Developing green purchasing relationships for the manufacturing industry: An evolutionary game theory perspective. Int. J. Prod. Econ. 2015, 166, 155-162. [CrossRef]

22. Xie, G. Cooperative strategies for sustainability in a decentralized supply chain with competing suppliers. J. Clean. Prod. 2016, 113, 807-821. [CrossRef]

23. Seuring, S. A review of modeling approaches for sustainable supply chain management. Decis. Support Syst. 2013, 54, 1513-1520. [CrossRef]

24. Liu, J.; Xie, K. Emergency supplies requisition negotiation principle of government in disasters. Kybernetes 2016, 45, 1174-1193. [CrossRef]

25. Zhi, B.; Liu, X.; Chen, J.; Jia, F. Collaborative carbon emission reduction in supply chains: An evolutionary game-theoretic study. Manag. Decis. 2019, 57, 1087-1107. [CrossRef]

26. Chen, W.; Tseng, C.L.; Sunny Yang, S.J. Improving hand hygiene process compliance through process monitoring in healthcare. Manuf. Serv. Oper. Manag. 2019, 22, 645-867. [CrossRef]

27. Du, L.; Qian, L. The government's mobilization strategy following a disaster in the Chinese context: An evolutionary game theory analysis. Nat. Hazards 2016, 80, 1411-1424. [CrossRef]

28. De, A.; Wang, J.; Tiwari, M.K. Fuel bunker management strategies within sustainable container shipping operation considering disruption and recovery policies. IEEE Trans. Eng. Manag. 2019, 1-23. [CrossRef]

29. De, A.; Wang, J.; Tiwari, M.K. Hybridizing basic variable neighborhood search with particle swarm optimization for solving sustainable ship routing and bunker management problem. IEEE Trans. Intell. Transp. Syst. 2020, 21, 986-997. [CrossRef]

30. De, A.; Choudhary, A.; Turkay, M.; Tiwari, M.K. Bunkering policies for a fuel bunker management problem for liner shipping networks. Eur. J. Oper. Res. 2019. [CrossRef]

31. Goswami, M.; De, A.; Habibi, M.K.K.; Daultani, Y. Examining freight performance of third-party logistics providers within the automotive industry in India: An environmental sustainability perspective. Int. J. Prod. Res. 2020. [CrossRef]

32. De, A.; Mogale, D.G.; Zhang, M.; Pratap, S.; Kumar, S.K.; Huang, G.Q. Multi-period multi-echelon inventory transportation problem considering stakeholders behavioural tendencies. Int. J. Prod. Econ. 2020, 225, 107566. [CrossRef]

33. Hofstra, N.; Dullaert, W.; De Leeuw, S.; Spiliotopoulou, E. Individual goals and social preferences in operational decisions. Int. J. Oper. Prod. Manag. 2019, 39, 116-137. [CrossRef]

34. Bealt, J.; Fernández Barrera, J.C.; Mansouri, S.A. Collaborative relationships between logistics service providers and humanitarian organizations during disaster relief operations. J. Humanit. Logist. Supply Chain Manag. 2016, 6, 118-144. [CrossRef]

35. Tong, Y.; Li, Y. External intervention or internal coordination? Incentives to promote sustainable development through green supply chains. Sustainability 2018, 10, 2857. [CrossRef]

36. Sheu, J.; Pan, C. Relief supply collaboration for emergency logistics responses to large-scale disasters. Transp. A Transp. Sci. 2015, 11, 210-242. [CrossRef]

37. Regis-Hernández, F.; Mora-Vargas, J.; Ruíz, A. A multi-criteria vertical coordination framework for a reliable aid distribution. J. Ind. Eng. Manag. 2017, 10, 789-815. [CrossRef]

38. Geng, S.; Hou, H.; Zhang, S. Multi-criteria location model of emergency shelters in humanitarian logistics. Sustainability 2020, 12, 1759. [CrossRef]

39. Nikkhoo, F.; Bozorgi-Amiri, A.; Heydari, J. Coordination of relief items procurement in humanitarian logistic based on quantity flexibility contract. Int. J. Disast. Risk Reduct. 2018, 31, 331-340. [CrossRef]

40. Zhang, J.; Wang, Z.; Ren, F. Optimization of humanitarian relief supply chain reliability: A case study of the Ya'an earthquake. Ann. Oper. Res. 2019, 283, 1551-1572. [CrossRef]

41. Grange, R.; Heaslip, G.; McMullan, C. Coordination to choreography: The evolution of humanitarian supply chains. J. Humanit. Logist. Supply Chain Manag. 2019, 10, 21-44. [CrossRef]

42. Schulz, S.F.; Blecken, A. Horizontal cooperation in disaster relief logistics: Benefits and impediments. Int. J. Phys. Distrib. Logist. Manag. 2010, 40, 636-656. [CrossRef]

43. McLachlin, R.; Larson, P.D. Building humanitarian supply chain relationships: Lessons from leading practitioners. J. Humanit. Logist. Supply Chain Manag. 2011, 1, 32-49. [CrossRef] 
44. Akhtar, P.; Marr, N.E.; Garnevska, E.V. Coordination in humanitarian relief chains: Chain coordinators. J. Humanit. Logist. Supply Chain Manag. 2012, 1, 85-103. [CrossRef]

45. Corsini, L.; Moultrie, J. Design for social sustainability: Using digital fabrication in the humanitarian and development sector. Sustainability 2019, 11, 3562. [CrossRef]

46. Martin, E.; Nolte, I.; Vitolo, E. The four Cs of disaster partnering: Communication, cooperation, coordination and collaboration. Disasters 2016, 40, 621-643. [CrossRef] [PubMed]

47. Leitner, R.; Meizer, F.; Prochazka, M.; Sihn, W. Structural concepts for horizontal cooperation to increase efficiency in logistics. CIRP J. Manuf. Sci. Technol. 2011, 4, 332-337. [CrossRef]

48. Chiappetta Jabbour, C.J.; Sobreiro, V.A.; Lopes De Sousa Jabbour, A.B.; de Souza Campos, L.M.; Mariano, E.B.; Renwick, D.W.S. An analysis of the literature on humanitarian logistics and supply chain management: Paving the way for future studies. Ann. Oper. Res. 2019, 283, 289-307. [CrossRef]

49. Lozano, S.; Moreno, P.; Adenso-Díaz, B.; Algaba, E. Cooperative game theory approach to allocating benefits of horizontal cooperation. Eur. J. Oper. Res. 2013, 229, 444-452. [CrossRef]

50. Toyasaki, F.; Arikan, E.; Silbermayr, L.; Falagara Sigala, I. Disaster relief inventory management: Horizontal cooperation between humanitarian organizations. Prod. Oper. Manag. 2017, 26, 1221-1237. [CrossRef]

51. Fathalikhani, S.; Hafezalkotob, A.; Soltani, R. Cooperation and coopetition among humanitarian organizations. Kybernetes 2018, 47, 1642-1663. [CrossRef]

52. Fathalikhani, S.; Hafezalkotob, A.; Soltani, R. Government intervention on cooperation, competition, and coopetition of humanitarian supply chains. Soc. Econ. Plan. Sci. 2020,69, 100715. [CrossRef]

53. Moshtari, M. Inter-organizational fit, relationship management capability, and collaborative performance within a humanitarian setting. Prod. Oper. Manag. 2016, 9, 1542-1557. [CrossRef]

54. Lu, Q.; Goh, M.; De Souza, R. An empirical investigation of swift trust in humanitarian logistics operations. J. Humanit. Logist. Supply Chain Manag. 2018, 8, 70-86. [CrossRef]

55. Awasthy, P.; Gopakumar, K.V.; Gouda, S.K.; Haldar, T. Trust in humanitarian operations: A content analytic approach for an Indian NGO. Int. J. Prod. Res. 2019, 57, 2626-2641. [CrossRef]

56. Schneiker, A. Why trust you? Security cooperation within humanitarian NGO networks. Disasters 2019, 44, 25-43. [CrossRef]

57. Blome, R.D.N.A. Swift trust and commitment: The missing links for humanitarian supply chain coordination? Ann. Oper. Res. 2019, 283, 159-177.

58. Prasanna, S.R.; Haavisto, I. Collaboration in humanitarian supply chains: An organisational culture framework. Int. J. Prod. Res. 2018, 56, 5611-5625. [CrossRef]

59. Nolte, I.M. Interorganizational collaborations for humanitarian aid: An analysis of partnership, community, and single organization outcomes. Public Perform. Manag. 2018, 41, 596-619. [CrossRef]

60. Yang, A. When transnational civil network meets local context: An exploratory hyperlink network analysis of Northern/Southern NGOs' virtual network in China. J. Int. Intercult. Commun. 2013, 1, 40-60. [CrossRef]

61. Apte, A.; Gonçalves, P.; Yoho, K. Capabilities and competencies in humanitarian operations. J. Humanit. Logist. Supply Chain Manag. 2016, 6, 240-258. [CrossRef]

62. Khieng, S.; Dahles, H. Resource dependence and effects of funding diversification strategies among NGOs in Cambodia. Voluntas Int. J. Volunt. Nonprofit Organ. 2015, 26, 1412-1437. [CrossRef]

63. Avellaneda, C.N.; Johansen, M.; Suzuki, K. What drives Japanese INGOs to operate in Latin American Countries? Int. J. Public Adm. 2017, 8, 670-683. [CrossRef]

64. Day, J.M.; Melnyk, S.A.; Larson, P.D.; Davis, E.W.; Whybark, D.C. Humanitarian and disaster relief supply chains: A matter of life and death. Supply Chain Manag. Int. J. 2012, 48, 21-36. [CrossRef]

65. Maghsoudi, A.; Zailani, S.; Ramayah, T.; Pazirandeh, A. Coordination of efforts in disaster relief supply chains: The moderating role of resource scarcity and redundancy. Int. J. Logist. Res. Appl. 2018, 21, 407-430. [CrossRef]

66. Tran, L.; AbouAssi, K. Local organizational determinants of local-international NGO collaboration. Public Manag. Rev. 2020. [CrossRef]

67. Li, X.; Ramshani, M.; Huang, Y. Cooperative maximal covering models for humanitarian relief chain management. Comput. Ind. Eng. 2018, 119, 301-308. [CrossRef]

68. Moshtari, M.; Gonçalves, P. Factors influencing interorganizational collaboration within a disaster relief context. Voluntas Int. J. Volunt. Nonprofit Organ. 2017, 28, 1673-1694. [CrossRef] 
69. Garcia, C.; Rabadi, G.; Handy, F. Dynamic resource allocation and coordination for high-load crisis volunteer management. J. Humanit. Logist. Supply Chain Manag. 2018, 8, 533-556. [CrossRef]

70. Simsa, R.; Rameder, P.; Aghamanoukjan, A.; Totter, M. Spontaneous volunteering in social crises: Self-organization and coordination. Nonprofit Volunt. Sec. Q. 2019, 48, 103S-122S. [CrossRef]

71. Yadav, D.K.; Barve, A. Analysis of critical success factors of humanitarian supply chain: An application of Interpretive structural modeling. Int. J. Disast. Risk Reduct. 2015, 12, 213-225. [CrossRef]

72. Cao, C.; Li, C.; Yang, Q.; Zhang, F. Multi-objective optimization model of emergency organization allocation for sustainable disaster supply chain. Sustainability 2017, 9, 2103. [CrossRef]

73. Altay, N.; Pal, R. Information diffusion among agents: Implications for humanitarian operations. Prod. Oper. Manag. 2014, 23, 1015-1027. [CrossRef]

74. Maghsoudi, A.; Pazirandeh, A. Visibility, resource sharing and performance in supply chain relationships: Insights from humanitarian practitioners. Supply Chain Manag. Int. J. 2016, 21, 125-139. [CrossRef]

75. Muggah, R. The effects of stabilisation of humanitarian action in Haiti. Disasters 2010, 34, 444-463. [CrossRef] [PubMed]

76. Rathi, D.; Given, L.M.; Forcier, E. Interorganisational partnerships and knowledge sharing: The perspective of non-profit organizations (NPOs). J. Knowl. Manag. 2014, 18, 867-885. [CrossRef]

77. Friedman, D. Evolutionary games in economics. Econometrica 1991, 59, 637-666. [CrossRef]

78. Hao, C.; Du, Q.; Huang, Y.; Shao, L.; Yan, Y. Evolutionary game analysis on knowledge-sharing behavior in the construction supply chain. Sustainability 2019, 11, 5319. [CrossRef]

79. Spiegel, P.; Ratnayake, R.; Hellman, N.; Ververs, M.; Ngwa, M.; Wise, P.H.; Lantagne, D. Responding to epidemics in large-scale humanitarian crises: A case study of the cholera response in Yemen, 2016-2018. BMJ Global Health 2019, 4, e1709. [CrossRef]

80. Nohrstedt, D.; Bynander, F.; Parker, C.; Hart, P.T. Managing crises collaboratively: Prospects and Problems-A Systematic Literature Review. Perspect. Public Manag. Gov. 2018, 1, 257-271.

81. Cheng, W.; Appolloni, A.; D'Amato, A.; Zhu, Q. Green public procurement, missing concepts and future trends-A critical review. J. Clean. Prod. 2018, 176, 770-784. [CrossRef]

82. Appolloni, A.; D'Amato, A.; Cheng, W. Is public procurement going green? Experiences and open issues. In The Applied Law and Economics of Public Procurement: The Economics of Legal Relationships; Piga, G., Treumer, S., Eds.; Routledge Taylor \& Francis Group: London, UK; New York, NY, USA, 2012; pp. 111-132.

83. Testa, F.; Nucci, B.; Iraldo, F.; Appolloni, A.; Daddi, T. Removing obstacles to the implementation of LCA among SMEs: A collective strategy for the valorization of Recycled Cardato. J. Clean. Prod. 2017, 156, 923-931. [CrossRef]

84. Appolloni, A.; Sun, H.; Fu, J.; Li, X. Green procurement in the private sector: A state of the art review between 1996 and 2013. J. Clean. Prod. 2014, 85, 122-133. [CrossRef]

(C) 2020 by the authors. Licensee MDPI, Basel, Switzerland. This article is an open access article distributed under the terms and conditions of the Creative Commons Attribution (CC BY) license (http://creativecommons.org/licenses/by/4.0/). 